\title{
Subchronic exposure to deoxynivalenol exerts slight effect on the immune system and liver morphology of growing rabbits
}

\author{
Mariam Kachlek ${ }^{1}$, Judit Szabó-Fodor ${ }^{2}$, András Szabó1, István Bors ${ }^{2}$, Chiara Celia ${ }^{1,3}$, \\ Zsolt Gerencsér ${ }^{1}$, Zsolt Matics ${ }^{1}$, Zsolt Szendrö ${ }^{1}$, Tamás Tuboly ${ }^{4}$, Erika Balogh-Zándoki ${ }^{5}$, \\ Róbert Glávits ${ }^{6}$, Antonella Dalle Zotte ${ }^{3}$, Melinda Kovács ${ }^{1,2}$ \\ ${ }^{1}$ Kaposvár University, Faculty of Agricultural and Environmental Sciences, \\ Kaposvár, Hungary \\ ${ }^{2}$ MTA-KE Mycotoxins in the Food Chain Research Group, Kaposvár, Hungary \\ ${ }^{3}$ University of Padova, Department of Animal Medicine, Production and Health, \\ Padova, Italy \\ ${ }^{4}$ Faculty of Veterinary Science, Szent István University, Budapest, Hungary; \\ ${ }^{5}$ Faculty of Agricultural and Environmental Sciences, Szent István University, \\ Gödöllö, Hungary \\ ${ }^{6}$ Autopsy KKT, Budapest, Hungary \\ Received July 7, 2016 \\ Accepted February 17. 2017
}

\begin{abstract}
As the most common grain contaminant worldwide, deoxynivalenol is of high importance despite its low toxicity compared to other trichothecene mycotoxins. Data on the effects of deoxynivalenol in rabbits are scarce. Thus, the aim of this study was to investigate the effects of dietary deoxynivalenol fed at a high level $(10 \mathrm{mg} / \mathrm{kg}$ of feed $)$ on the productive performance, blood indices, immunological variables, histopathological changes, and genotoxicity in rabbits. Forty-eight Pannon White rabbits were exposed to contaminated diets for three weeks. Despite its high concentration, deoxynivalenol did not affect the feed intake, body weight, and body weight gain. Liver and kidney function was not affected, as shown by the clinical chemistry indices. Conversely, in two rabbits the toxin caused mild fibrosis of the liver, without degenerative changes of the hepatocytes. No genotoxicity could be observed either. Gut cytokines and the phagocytic activity of the macrophages did not differ significantly. The percentage of neutrophils was significantly lower, whereas that of eosinophils was significantly higher in the toxin-fed group. Deoxynivalenol did not cause significant changes in gut and villus morphology. In 4 out of the 6 deoxynivalenol-treated animals, the ratio of lymphoblast proliferation and simultaneous apoptosis shifted towards apoptosis in the gut-associated lymphoid tissue. In the central part of the lymphoid follicles of the spleen, lymphocyte depletion and follicular atrophy could be detected. It can be concluded that rabbits are less sensitive to deoxynivalenol, but the findings confirm that this Fusarium toxin is capable of modulating the immune response.
\end{abstract}

Mycotoxin, immune response, histology, blood indices

Mycotoxins are secondary metabolites of filamentous fungi occurring worldwide. Despite being the least toxic trichothecene, the ubiquitous occurrence of deoxynivalenol (DON) in grains increases its importance for food and feed safety. The pig is the most sensitive, whereas ruminants are the least sensitive animal species to DON (Pestka and Smolinski 2005; Pestka 2007; Sobrova et al. 2010). Monogastric animals are extremely prone to growth and body weight gain suppression upon DON exposure. Deoxynivalenol possesses immunomodulatory properties as well (Pestka and Smolinski 2005). To the best of our knowledge, only few experiments have been conducted with DON in rabbits (Khera et al. 1986; Hewitt et al. 2012). The aim of this study, therefore, was to investigate the effects of $10 \mathrm{ppm}(\mathrm{mg} / \mathrm{kg}$ feed) of dietary DON which is twice as much as the highest guidance value

Address for correspondence:

Mariam Kachlek,

Faculty of Agricultural and Environmental Sciences

Kaposvár University

Phone: +306997167752

Guba S. u. 40, H-7400 Kaposvár, Hungary 
established by the EC in 2006 for DON in complementary and complete feeding stuffs $(2006 / 576 / E C)$. The indices examined in growing rabbits were productive performance, blood variables, immunology, histopathology, and genotoxicity.

\section{Materials and Methods}

All chemicals used were purchased from Sigma Aldrich (Schnelldorf, Germany) if not stated otherwise.

The experimental protocol was authorized by the Food Chain Safety and Animal Health Directorate of the Somogy County Agricultural Office, under permission number SOI/31/1679-11/2014.

Animals, experimental design and sample collection

Forty-eight weaned, 7-week-old Pannon White rabbits were housed in metal wire mesh cages $(3$ rabbits per cage). After one week of acclimatization, the 8-week-old rabbits started receiving the toxin-containing diet while two groups were formed; the control $(\mathrm{C} ; \mathrm{n}=24)$, and the toxin $(\mathrm{T} ; \mathrm{n}=24)$ group. The animals were checked daily for mortality and morbidity; weight and feed intake were recorded weekly. Blood sampling was performed on day 21 from the marginal ear vein of 6 rabbits into native and heparinized tubes. Red blood cell (RBC) haemolysate was prepared by adding $900 \mu 1$ sterile distilled water to $100 \mu 1$ washed RBC bulk. After 3 weeks of exposure, 6 rabbits from both groups were euthanized by cervical dislocation and exsanguinated. Small intestinal samples were taken from the jejunum ( $1 \mathrm{~cm}$ before the Meckel's diverticulum), ileum $(1 \mathrm{~cm}$ before the ileocaecal junction), liver, spleen, kidneys and heart for histopathological examination. A sample from the mid-section of the jejunum was taken for cytokine measurements.

Mycotoxin production and diet

The toxin was produced according to Szabó-Fodor et al. (2015) with a slight modification; for the production of DON, Fusarium graminearum strain number IFA 77 was used (BOKU, Tulln, Austria). The mycotoxin content of the diet was checked using the LC-MS system (LC-MS 2020 Single Quadrupole Mass Spectrometer, LC-20AD pumps with DGU-20A degasser, SIL-20ACHT autosampler, CTO-20-AC Column Owen and CBM-20A Interface, SHIMADZU, Kyoto, Japan). The detection limits for $\mathrm{FB}_{1}, \mathrm{~T}-2$, zearalenone, deoxynivalenol, ochratoxin $\mathrm{A}$, and aflatoxin B1 were $10,3,5,3,10$ and $10 \mu \mathrm{g} / \mathrm{kg}$, respectively. The DON's concentration in the contaminated diet was $10.1 \mathrm{mg} / \mathrm{kg}$ and no other mycotoxins (including $\mathrm{T}-2$, zearalenone, ochratoxin $\mathrm{A}$, aflatoxin $\mathrm{B}_{1}$ ) were present in detectable quantities in the diets. The control diet was free of DON.

The diet contained $10.3 \mathrm{MJ} / \mathrm{kg}$ digestible energy, $15.5 \%$ crude protein, $2.8 \%$ crude fat and $35.3 \%$ neutral detergent fibre calculated on a dry matter basis. Two different batches were prepared: a control batch and a batch contaminated with $10 \mathrm{mg} / \mathrm{kg}$ DON. Feed was provided ad libitum and the animals had free access to drinking water provided from pacifiers.

\section{Haematology, clinical chemistry, antioxidant properties}

Haematological and serum clinical chemical properties were determined in a professional veterinary laboratory (Vet-med Laboratory, Budapest, Hungary), using a Cell-Dyn 3500 automated haematology analyser (Abbott, Chicago, USA) and a Roche Hitachi 912 Chemistry Analyser (Hitachi, Tokyo, Japan) with commercial diagnostic kits (Diagnosticum Ltd., Budapest, Hungary).

Glutathione peroxidase (GSHPx) activity, reduced glutathione (GSH) and malondialdehyde (MDA) concentrations were measured in blood plasma and red blood cell $(1 / 9 \mathrm{v} / \mathrm{v})$ haemolysate, as described previously (Szabó-Fodor et al. 2015).

\section{Determination of immunity indicators}

Peripheral white blood cells (WBC) were isolated by density gradient centrifugation ( $400 \times g$ for $15 \mathrm{~min}$ ) using Ficoll-Paque (Pharmacia, USA) according to standard protocols. The number of viable PBLs was determined by trypan blue exclusion in a haemocytometer. The cells were diluted in DMEM supplemented with penicillin and streptomycin antibiotics and $10 \%$ foetal bovine serum. Cells were plated at $1 \times 10^{5}$ cells/well density into 6 well plates. The cultures were incubated for 4 days at $37{ }^{\circ} \mathrm{C}$ under $5 \% \mathrm{CO}_{2}$ tension. Phagocytic ability (PA) was determined with Congo-red stained yeast cells by incubating overnight at $37^{\circ} \mathrm{C}$, and expressed as percentage of phagocytic cells quantified from 100 cells observed under a microscope.

Cytokines (IL-1, IL-2, IFN- $\gamma$ ) were detected by reverse transcriptase real-time polymerase chain reaction (rt-RT-PCR), detecting mRNA. Whole blood was used for total ribonucleic acid (RNA) isolation with the Analytik Jena innuPREP Blood RNA Kit (Biometra, Germany), following the manufacturer's instructions. RNA templates were transcribed into complementary deoxyribonucleic acid (cDNA) by the Maxima First Strand cDNA Synthesis Kit for RT-qPCR (Fermentas, Lithuania) according to the manufacturer's protocol. Amplification using cytokinespecific primers was performed in an Eppendorf Realpex ${ }^{2}$ Mastercycler. Primers for IL-1 and -2 were designed using the Primer3 Programme (Rozen and Skaletsky 1999) and the available GenBank sequences. For IFN- $\gamma$, primers reported by Godornes et al. (2007) were used. The mixture was the following: $2 \mu \mathrm{l}$ cDNA solution, $5 \mu 110 \times$ DreamTaq Buffer, $2 \mu 1$ of $25 \mathrm{pmol} / \mu \mathrm{l}$ of each primer, $1 \mu \mathrm{l}$ of $1 \mathrm{mmol}$ dNTP Set (Fermentas), $2.5 \mu \mathrm{l} \mathrm{EVA}$ 
Green (Biotium, USA) and 0.2 DreamTaq ${ }^{\mathrm{TM}}$ DNA Polymerase, 5 U/ $\mu$ l DreamTaq ${ }^{\mathrm{TM}}$ DNA Polymerase $(5 \mathrm{U} / \mu 1$, Fermentas, USA) at a final volume of $20 \mu$. The PCR reactions were as follows: preheating at $95{ }^{\circ} \mathrm{C}$ for $5 \mathrm{~min}$, 40 cycles of $54^{\circ} \mathrm{C}$ for $30 \mathrm{~s}$, and $72^{\circ} \mathrm{C}$ for $45 \mathrm{~s}$, followed by a final extension step of $72^{\circ} \mathrm{C}$ for $7 \mathrm{~min}$.

\section{Histology}

Samples from the liver, heart, kidney, spleen and the small intestine were placed into $10 \%$ neutral buffered formaldehyde solution. Five $\mu \mathrm{m}$ thick sections were embedded in paraffin and stained with haematoxylin-eosin (HE). To assess gut morphology, the general status of the mucosa, the epithelial layer, the structure of the stratum villosum, the quality and quantity of the cells and the cytomorphology of the gut-associated lymphoid tissue (GALT) were examined. The ocular micrometric method was used to measure villus height (VH) and crypt depth (CD) (five villi were measured in each sample, and the mean values were calculated).

\section{Comet assay}

On day 21, comet assay was performed as described previously (Horvatovich et al. 2013) to assess DNA damage in the lymphocytes of rabbits, with the following modifications: after mixing $50 \mu 1$ of whole blood with $1 \mathrm{ml}$ of $1 \%$ low melting point (LMP) agarose, $140 \mu \mathrm{l}$ of this mixture were placed (in 2 drops) on a pre-coated (1\% normal melting point [NMP] agarose) slide and then immediately covered with a cover slip to avoid dehydration. Tail intensity (\% DNA in the tail) was determined with an epifluorescent microscope (B600 TiFL; optimum filter 4 and $\lambda=302 \mathrm{~nm}$; Optika, Italy) and Comet IV (version 4.3.1.) software, examining 100 comets per gel.

\section{Statistical analysis}

All data were analysed by IBM SPSS Statistics (version 19.0). Student's $t$-test was used and the level of significance was $P<0.05$.

\section{Results}

Feed intake, body weight and body weight gain were not significantly affected by the treatment (Table 1). The toxin-exposed rabbits did not show clinical signs, the feed refusal effect was not observed, and no animals died as a result of the toxin treatment.

Table 1. Production indicators (mean \pm S.D.) after exposing rabbits $(\mathrm{n}=6)$ to a feed containing $10 \mathrm{mg} / \mathrm{kg}$ deoxynivalenol.

\begin{tabular}{lccc}
\hline \multicolumn{3}{c}{ Feed intake $(\mathrm{g})$} \\
\hline Group & $0-7$ days & $7-14$ days & $14-21$ days \\
\hline Control & $170.2 \pm 20.5$ & $183.4 \pm 13.5$ & $192.2 \pm 20.8$ \\
DON & $157.3 \pm 26.7$ & $177.2 \pm 26.4$ & $191.8 \pm 27.0$ \\
& & Body weight $(\mathrm{g})$ & \\
\hline & Day 7 & Day 14 & Day 21 \\
Control & $2385.5 \pm 364.4$ & $2745.5 \pm 370.1$ & $3116.0 \pm 382.2$ \\
DON & $2277.4 \pm 540.5$ & $2660.9 \pm 501.8$ & $3200.8 \pm 333.9$ \\
& & Body weight gain $(\mathrm{g})$ & \\
\hline \multirow{3}{*}{ Control } & Day 7 & Day 14 & Day 21 \\
DON & $59.3 \pm 13.7$ & $54.1 \pm 9.1$ & $50.5 \pm 12.0$ \\
\hline & $50.7 \pm 19.3$ & $54.8 \pm 10.5$ & $57.5 \pm 13.5$ \\
\hline
\end{tabular}

The control group had a significantly higher neutrophil percentage. However, the percentages of monocytes and eosinophils were significantly higher in the toxin-treated group (Table 2). Serum total protein, albumin, glucose, triglyceride, cholesterol, urea and creatinine concentrations as well as alanine aminotransferase (ALT), aspartate aminotransferase (AST) and gamma-glutamyl transpeptidase (GGT) activities did not differ significantly according to treatment, and the mean values were within the physiological 
Table 2. Haematological indices (mean \pm S.D.) after exposing rabbits $(\mathrm{n}=6)$ to a feed containing $10 \mathrm{mg} / \mathrm{kg}$ deoxynivalenol.

\begin{tabular}{lcc}
\hline & \multicolumn{2}{c}{ Group } \\
\cline { 2 - 3 } Indicator & Control & DON \\
White blood cell count (G/l) & $4.0 \pm 0.9$ & $3.6 \pm 1.0$ \\
Red blood cell count (T/l) & $5.9 \pm 0.2$ & $5.7 \pm 0.5$ \\
Neutrophils (\%) & $71.8 \pm 2.6^{\mathrm{a}}$ & $64.5 \pm 6.7^{\mathrm{b}}$ \\
Lymphocytes (\%) & $17.5 \pm 5.1$ & $19.9 \pm 6.3$ \\
Monocytes (\%) & $8.7 \pm 4.2^{\mathrm{a}}$ & $13.2 \pm 2.1^{\mathrm{b}}$ \\
Eosinophils (\%) & $0.1 \pm 0.0^{\mathrm{a}}$ & $0.8 \pm 0.8^{\mathrm{b}}$ \\
Basophils (\%) & $1.3 \pm 1.8$ & $1.6 \pm 1.4$ \\
Haemoglobin (g/l) & $123.3 \pm 5.4$ & $122.5 \pm 5.5$ \\
Haematocrit (\%) & $45.2 \pm 2.0$ & $44.3 \pm 1.8$ \\
Platelets (g/l) & $254.3 \pm 153.8$ & $349.5 \pm 161.9$ \\
Mean corpuscular volume (fl) & $76.6 \pm 2.2$ & $78.1 \pm 4.1$ \\
Mean corpuscular haemoglobin (pg) & $20.9 \pm 0.6$ & $21.6 \pm 1.0$ \\
Mean corpuscular haemoglobin concentration (g/dl) & $27.4 \pm 0.2$ & $27.6 \pm 0.2$ \\
Red blood cell distribution width & $16.0 \pm 1.7$ & $15.1 \pm 0.9$ \\
\hline
\end{tabular}

a, $\mathrm{b}$ means within a row with different superscripts differ significantly $(P<0.05)$

DON $=$ deoxynivalenol

ranges (Harcourt-Brown 2002) (data not shown). The macrophage count was $372 \pm 19$ and $378 \pm 17$ per ml, and the phagocytic activity of macrophages was $72 \pm 8$ and $75 \pm 2 \%$ in the control and the toxin groups, respectively, without any significant difference. No significant differences were observed for any of the gut cytokines (IL-1, IL-2 and INF- $\gamma$ ) (Table 3) or the antioxidant properties measured (GSH, GSHPx and MDA) (Table 4).

Table 3. Level of some gut cytokines (mean \pm S.D.) and antioxidant properties (mean \pm S.D.) after exposing rabbits $(\mathrm{n}=6)$ to a feed containing $10 \mathrm{mg} / \mathrm{kg}$ deoxynivalenol.

\begin{tabular}{lcc}
\hline & Control & DON \\
\hline Interleukin-1 $^{1}$ & $16.9 \pm 0.5$ & $17.6 \pm 3.4$ \\
Interleukin-2 $^{1}$ & $11.2 \pm 2.8$ & $12.4 \pm 3.8$ \\
Interferon-gamma $^{1}$ & $12.2 \pm 2.6$ & $12.1 \pm 2.6$ \\
\hline
\end{tabular}

${ }^{1}$ Expressed in $\mathrm{Ct}$ values (cycle threshold, the number of cycles required for the fluorescent signal to cross the threshold)

DON $=$ deoxynivalenol

Deoxynivalenol did not exert a significant effect on gut and villus morphology. The morphology of the gut mucosa was normal and the epithelial layer of the villi was intact in both groups. Thickening and fusion of the villi could be observed in only one of the toxin-treated animals. As regards the GALT, in 4 out of the 6 DON-treated rabbits, the rate of lymphoblast proliferation and simultaneous apoptosis shifted towards apoptosis (Plate I, Fig. 1). The spleen was also affected by DON treatment in all animals. In the central part of the lymphoid follicles, in the Malpighian bodies, lymphocyte depletion resulting in smaller follicles (follicular atrophy) could be detected (Plate I, Fig. 2b) compared to the control animals (Plate I, Fig. 2a). Deoxynivalenol caused slight fibrosis in the liver, without 
Table 4. Level of the antioxidant properties (mean \pm S.D.) after exposing rabbits $(n=6)$ to a feed containing $10 \mathrm{mg} / \mathrm{kg}$ deoxynivalenol.

\begin{tabular}{lrr}
\hline & \multicolumn{1}{c}{ Control } & \multicolumn{1}{c}{ DON } \\
\hline In the red blood cell haemolysate & & \\
$\mathrm{GSH}^{1}(\mu \mathrm{mol} / \mathrm{g}$ protein) & $4.0 \pm 1.4$ & $4.8 \pm 0.8$ \\
$\mathrm{GSHPx}^{2}(\mathrm{E} / \mathrm{g}$ protein$)$ & $5.2 \pm 1.5$ & $5.1 \pm 2.5$ \\
$\mathrm{MDA}^{3}(\mathrm{nmol} / \mathrm{g})$ & $21.6 \pm 3.7$ & $22.2 \pm 4.6$ \\
in the blood plasma & & \\
$\mathrm{GSH}^{1}(\mu \mathrm{mol} / \mathrm{g}$ protein) & $4.4 \pm 0.1$ & $4.5 \pm 0.4$ \\
$\mathrm{GSHPx}^{2}(\mathrm{E} / \mathrm{g}$ protein) & $5.1 \pm 0.5$ & $5.2 \pm 0.5$ \\
$\mathrm{MDA}^{3}(\mathrm{nmol} / \mathrm{g})$ & $15.1 \pm 2.0$ & $14.2 \pm 3.3$ \\
\hline
\end{tabular}

${ }^{1} \mathrm{GSH}=$ glutathione $;{ }^{2} \mathrm{GSHPx}=$ glutathione peroxidase $;{ }^{3} \mathrm{MDA}=$ malondiadelhyde

$\mathrm{DON}=$ deoxynivalenol

degenerative alteration of the hepatocytes (Plate I, Fig. 3). Deoxynivalenol did not cause any pathological changes in either the heart or the kidneys.

According to the results obtained, DON did not prove to be genotoxic. The tail intensity was $28.6 \pm 9.1$ and $21.4 \pm 10.3$; the tail moment was $7.3 \pm 2.2$ and $8.5 \pm 4.4$ in the control and toxin-treated rabbits, respectively, without significant differences between the groups.

\section{Discussion}

Among the main adverse effects of DON, feed refusal with a subsequent reduction in feed intake and body weight gain are the most often encountered effects in most animal species studied. In our experiment, the feed refusal effect and its negative consequences were not observed despite the high dose of DON applied $(10 \mathrm{mg} / \mathrm{kg})$. In the study of Hewitt et al. (2012) DON $(0.25,4.2$ and $4.9 \mathrm{mg} / \mathrm{kg})$ did not affect feed consumption but increased the body weight gain, which was attributed to higher water consumption of the toxin-fed rabbits, compared to the control animals. The above-cited authors found some slight numerical differences in certain clinical chemical properties and a change in the number of eosinophilic granulocytes in the lamina propria of the gastrointestinal tract of rabbits fed the DON-containing diet. Based on these findings they concluded that rabbits could be adversely affected by Fusarium mycotoxins but appear to be less sensitive than other animal species. This is in contrast with the hypothesis that rabbits could be re-exposed to toxins through caecotrophy (Fekete et al. 1989), and thus it could be presumed that they are more sensitive to dietary toxin exposure than other monogastric animals.

Clinical chemical properties are indicators of the health status of animals and may indicate dysfunction or damage of different target organs, e.g. the liver, kidney, and heart. In our study no changes attributable to DON consumption were detected. The liver is considered to be the primary target organ of many mycotoxins including trichothecenes (such as DON) in most species examined (Bergsjo et al. 1993; Sun et al. 2014). In the present experiment DON caused slight fibrosis in the liver without degenerative alteration of the hepatocytes. The latter was confirmed by the fact that the activities of liver enzymes (AST, ALT and GGT) remained unchanged and within the physiological range.

In the present study DON at the dose applied had no effect on the antioxidant status of the animals. According to El Golli-Bennour and Bacha (2011) oxidative stress is not a major contributor to DON toxicity because it does not induce over-expression of Hsp70 and has a negligible effect on hydrogen peroxide and MDA production. While 
there are several in vitro studies on oxidative stress induced by $\mathrm{DON}$, in vivo studies are lacking as reviewed by Mishra et al. (2014): DON increased lipid peroxidation and altered the antioxidant status (GSH, GSHPx) in rats, mice and broiler chickens but it did not significantly alter antioxidant properties (MDA, TAS, GSHPx) in a study with broiler chicken and male pigs.

Reactive oxygen species (ROS) are able to oxidize DNA bases and cause DNA damage. Deoxynivalenol fed to broiler chickens at $10 \mathrm{mg} / \mathrm{kg}$ of feed for 5 weeks increased the percentage of tail DNA (tail intensity) in the comet assay performed with the isolated lymphocytes (Frankic et al. 2006). Although DON did not increase MDA in the plasma or liver in the above-cited study, the oxidative stress pathway was suggested as a plausible mechanism for the observed DNA damage. Similarly, DNA damage was reported by Frankic et al. (2008) in pigs (4 mg DON/kg of feed for 14 days) and Awad et al. (2012) in chicken (10 mg DON/kg of feed for 35 days). According to the literature cited DON is considered to have negligible oxidative stress inducing effect and thus, it is supposed that DON is directly genotoxic or acts via different epigenetic mechanisms (e.g. DNA-adduct formation), causing DNA fragmentation. We concluded that $10 \mathrm{mg} / \mathrm{kg} \mathrm{DON}$ in the feed had no significant effect on the antioxidant status of the rabbits, and no direct or indirect (oxidative stress induced) genotoxicity could be observed.

Neither the number nor the activity of macrophages was influenced by $10 \mathrm{mg} \mathrm{DON} / \mathrm{kg}$ of feed. As mycotoxins enter the animals' body mostly via the consumption of contaminated feed, the gastrointestinal tract is the first organ exposed to them. This was the reason why some of the gut cytokines (IL-1, IL-2, IFN- $\gamma$ ) were studied, which have not yet been investigated in rabbits. In domestic pigs, a lower expression of IL- $1 \beta$ and IL-8 occurred in the blood and ileal tissue after the feeding of low doses of DON (Becker et al. 2011). In the present experiment there was no measurable difference between the two groups regarding the cytokines investigated. Although no pronounced immunomodulatory effect of DON was observed in this experiment, the histological findings revealed lymphocyte depletion and follicular atrophy in the spleen of DON-treated rabbits. In the GALT, the rate of lymphoblast apoptosis increased in the DON-treated animals. These observations support the results suggesting that DON may alter the functioning of the immune system.

One of the most pronounced effects of DON in this experiment was the higher monocyte and eosinophil and the lower neutrophil ratio within the white blood cells. As the absolute monocyte count was not influenced significantly by the treatment, the shift in the ratio of the different leukocytes was due to the decrease of neutrophil and the increase in eosinophil cell counts. As neutrophil granulocytes are the most numerous among the phagocytic cells, impairment of the non-specific immune response might be a consequence. Upon activation, eosinophils also become capable of phagocytosis; they secrete a range of toxic proteins and free radicals that are effective in killing parasites, but may also cause tissue damage through an allergic reaction. While the effect of DON on the innate and the adaptive immune system has been thoroughly studied both in vitro and in vivo, most information concerns macrophages, cytokine production and expression, lymphocytes and natural killer cells, and very few data are available on the effect exerted by DON on neutrophil and eosinophil granulocytes. The haematotoxicity of other trichothecene toxins (T-2 toxin and diacetoxyscirpenol) has been thoroughly investigated but DON has been less studied. Deoxynivalenol preferentially inhibits late-aggregate-forming cells, specifically colonyforming cells, in the rat, but being $\times 100$ less toxic than T-2 (Lautraite et al. 1997). According to Chowdhury et al. (2005) $12 \mathrm{mg} / \mathrm{kg}$ DON in the feed was not haematotoxic and did not affect the ratio of peripheral blood leukocytes in laying hens.

The intestinal villi increase the surface area available for brush border digestion and nutrient absorption. In a meta-analysis of experiments on the modulation of intestinal functions following mycotoxin ingestion, Grenier and Applegate (2013) review 
11 experiments about DON and nutrient uptake, which are limited to poultry and pigs. Some villous abnormalities (reduced villus height, villus fusion, and atrophy) after DON exposure were described in pigs (Bracarense et al. 2012) and poultry (Awad et al. 2006). In our experiment, thickening and fusion of the villi could be observed in only one of the toxin-treated animals. Thus, the lack of a pronounced effect on the gut may also explain the fact that the toxin-exposed animals had a similar weight gain as the controls.

As it was shown in the present study, rabbits seem to be less sensitive to DON compared to other mammalian animal species. The most sensitive target was the immune system but no secondary negative effect (infection) was found. Future studies are required to explore the reason of the relative resistance of rabbits against DON.

\section{Acknowledgements}

This research was supported by the National Scientific Research Fund (OTKA 100810) to MK and the János Bolyai Research Grant of the Hungarian Academy of Sciences (BO/499/13) to JSzF.

\section{References}

Awad W, Böhm J, Razzali-Fazeli E, Zentek J 2006: Effects of feeding deoxynivalenol-contaminated wheat on growth performance, organ weights, and histological parameters of intestine of broiler chickens. J Anim Physiol Anim Nutr 90: 32-37

Awad W, Ghareeb K, Dadak A, Gille L, Staniek K, Hess M, Böhm J 2012: Genotoxic effects of deoxynivalenol in broiler chickens fed low-protein feeds. Poultry Sci 91: 550-555

Becker C, Reiter M, Pfaffl MW, Meyer HHD, Bauer J, Meyer KHD 2011: Expression of immune relevant genes in pigs under the influence of low doses of deoxynivalenol (DON). Myc Res 27: 287

Bergsjo B, Langseth W, Nafstad I, Jansen JH, Larsen HJS 1993: The effects of naturally deoxynivalenolcontaminated oats on the clinical condition, blood parameters, performance and carcass composition of growing pigs. Vet Res Commun 17: 283-294

Bracarense AFL, Lucioli J, Grenier B, Drochiunas Pacheco G, Moll WD, Schatzmayr G, Oswald IP 2012: Chronic ingestion of deoxynivalenol and fumonisin, alone and in interaction, induces morphological and immunological changes in the intestine of piglets. Br J Nutr 107: 1776-1786

Chowdhury SR, Smith TK, Boermans HJ, Woodward B 2005: Effects of feed-borne Fusarium mycotoxins on haematology and immunology of laying hens. Poultry Sci 84: 1841-1850

El Golli-Bennour E, Bacha H 2011: Hsp70 expression as biomarkers of oxidative stress: Mycotoxins' exploration. Toxicology 287: 1-7

European Commission 2006: Commission Recommendation of 17 August 2006 on the presence of deoxynivalenol, zearalenone, ochratoxin A, T-2 and HT-2 and fumonisins in products intended for animal feeding. OJ L 229: 7-9

Fekete S, Tamas J, Vanyi A, Glavits R, Bata A 1989: Effect of T-2 toxin fed in sublethal quantity on digestion in the rabbit (in Hungarian). Magy Allatorvosok 44: 739-740

Frankic T, Pajk T, Rezar V, Levart A, Salobir J 2006: The role of dietary nucleotides in reduction of DNA damage induced by T-2 toxin and deoxynivalenol in chicken leukocytes. Food Chem Toxicol 44: 1838-1844

Frankic T, Salobir J, Rezar V 2008: The effect of vitamin E supplementation on reduction of lymphocyte DNA damage induced by T-2 toxin and deoxynivalenol in weaned pigs. Anim Feed Sci Technol 141: 274-286

Godornes C, Leader BT, Molini BJ, Centurion-Lara A, Lukehart SA 2007: Quantitation of rabbit cytokine mRNA by real time RT-PCR. Cytokine 38: 1-7

Grenier B, Applegate TJ 2013: Modulation of intestinal functions following mycotoxin ingestion: meta-analysis of published experiments in animals. Toxins 5: 396-430

Harcourt-Brown F 2002: Textbook of Rabbit Medicine. Elsevier Press, Oxford, 410 p.

Hewitt MA, Girgis GN, Brash M, Smith TK 2012: Effects of feed-borne Fusarium mycotoxins on performance, serum chemistry, and intestinal histology of New Zealand White fryer rabbits. J Anim Sci 90: 4833-4838

Horvatovich K, Hafner D, Bodnár Zs, Berta G, Hancz Cs, Dutton MF, Kovács M 2013: Dose related genotoxic effect of T-2 toxin measured by comet assay using peripheral blood mononuclear cells of healthy pigs. Acta Vet Hung 61: 175-186

Khera KS, Whalen C, Angers G 1986: A teratology study on vomitoxin (4-deoxynivalenol) in rabbits. Food Chem Toxicol 24: 421-424

Lautraite S, Parent-Massin D, Rio B, Hoellinger H 1997: In vitro toxicity induced by deoxynivalenol (DON) on human and rat granulo-monocytic progenitors. Cell Biol Toxicol 13: 175-183

Mishra S, Dwivedi PD, Pandey HP, Das M 2014: Role of oxidative stress in deoxynivalenol induced toxicity. Food Chem Toxicol 72: 20-29

Pestka JJ, Smolinski AT 2005: Deoxynivalenol: Toxicology and potential effects on humans. J Toxicol Environ Health B Crit Rev 8: 39-69 
Pestka JJ 2007: Deoxynivalenol: Toxicity, mechanisms and animal health risks. Anim Feed Sci Technol 137: 283-298

Rozen S, Skaletsky H 1999: Primer3 on the WWW for general users and for biologist programmers. In: Krawetz S, Misener S (Eds): Bioinformatics Methods and Protocols: Methods in Molecular Biology. Humana Press, Totowa, New Jersey, pp. 365-386

Sobrova P, Adam V, Vasatkova A, Beklova M, Zeman L, Kizek R 2010: Deoxynivalenol and its toxicity. Interdisc Toxicol 3: 94-99

Sun LH, Lei MY, Zhang NY, Zhao L, Krumm CS, Qi DS 2014: Hepatotoxic effects of mycotoxin combinations in mice. Food Chem Toxicol 74: 289-293

Szabó Fodor J, Kachlek M, Cseh S, Somoskői B, Szabó A, Blochné Bodnár Zs, Tornyos G, Mézes M, Balogh K, Glávits R, Hafner D, Kovács M 2015: Individual and combined effects of subchronic exposure of three Fusarium toxins (fumonisin B, deoxynivalenol and zearalenone) in rabbit bucks. J Clin Toxicol http://dx.doi. org/10.4172/2161-0495.1000264 
Plate I

Kachlek M. et al.: Subchronic exposure... pp.37-44

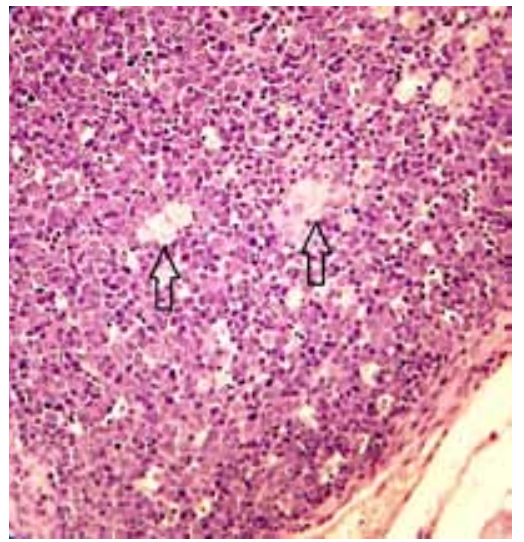

Fig. 1. Jejunal mucosa of a rabbit exposed to deoxynivalenol. Increased apoptotic processes in the lymphatic tissue of Peyer's patches (haematoxylin and eosin stain, $\times 400$ )

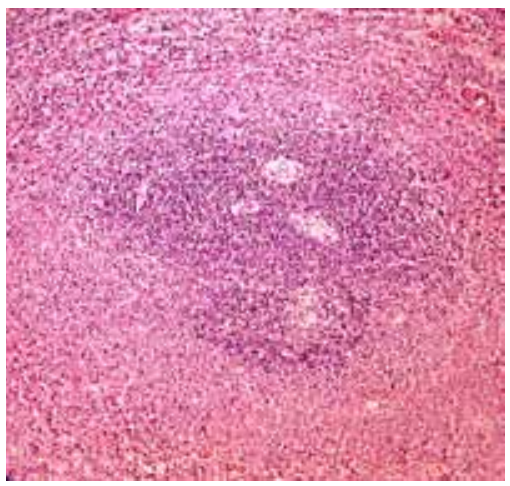

Fig. 2a. In control animals the lymphatic nodules in the spleen are big and rich in lymphocytes (haematoxylin and eosin stain, $\times 200$ )

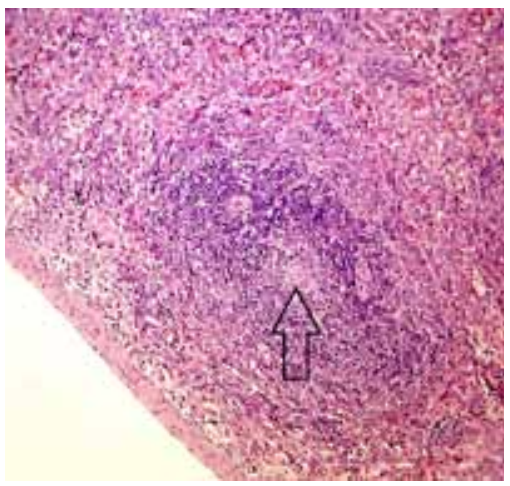

Fig. 2b. In deoxynivalenol-exposed rabbits the Malpighian body is smaller and lymphocyte depletion can be detected (haematoxylin and eosin stain, $\times 200$ )

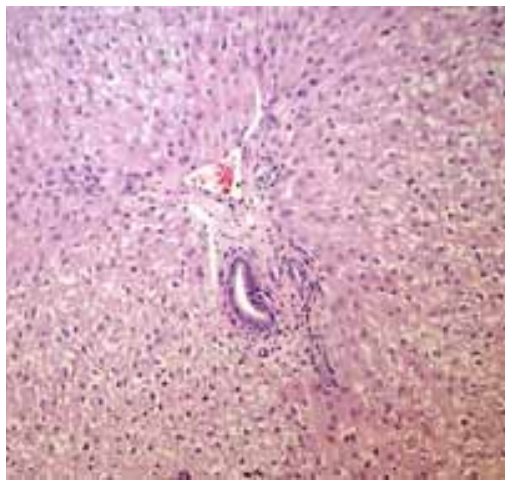

Fig. 3. Interstitial fibrosis (proliferation of fibres) in the liver of deoxynivalenol-exposed rabbits (haematoxylin and eosin stain, $\times 200$ ) 